\title{
DISTRIBUIÇÃO E DINÂMICA DA ÁREA DE COPA NA ARBORIZAÇÃO DE RUAS DE CURITIBA, PARANÁ, BRASIL, NO PERÍODO DE 1984-2010¹
}

\author{
Rogério Bobrowski² e Daniela Biondi ${ }^{3}$
}

\begin{abstract}
RESUMO - Diante dos impactos advindos do processo de urbanização, uma das formas de favorecer a melhoria da qualidade de vida da população das cidades é realizar o planejamento e plantio de árvores, em áreas públicas ou particulares. Os benefícios ambientais ou socioeconômicos almejados com a arborização de ruas provêm, em maior parte, da copa das árvores e do manto de cobertura formado nas ruas. Dessa forma, objetivou-se com esta pesquisa analisar a distribuição e dinâmica de classes de área de copa de árvores avaliadas em dois inventários conduzidos na arborização de ruas da cidade de Curitiba, em 1984 e 2010. A distribuição dos dados em classes de área de copa, para o total de dados amostrados e para cada parcela, demonstrou que há tendência para uma curva de distribuição do tipo decrescente, típica de povoamentos multiâneos e multiespecíficos, tanto para o ano de 1984 quanto para o ano de 2010, com maior frequência de indivíduos na classe de área de copa de $0-50 \mathrm{~m}^{2}$. Entretanto, quando analisados os dados das principais espécies, constatou-se que para algumas delas a curva de distribuição mudou de decrescente, em 1984, para unimodal, em 2010. Houve maior ingresso de árvores remanescentes nas classes de $50+100 \mathrm{~m}^{2}$ e $100-150 \mathrm{~m}^{2}$ e maior remoção da classe de $0-50 \mathrm{~m}^{2}$. Conclui-se que foi possível compreender, em parte, características comportamentais de espécies e verificar sinais de amadurecimento da arborização de ruas de Curitiba quando analisada 26 anos depois.
\end{abstract}

Palavras-chave: Cobertura arbórea, Sombreamento, Remedição de árvores e Evolução da arborização urbana

\section{DISTRIBUTION AND DYNAMICS OF CROWN AREA ON STREET TREES OF CURITIBA, PARANÁ, BRAZIL, IN THE PERIOD 1984-2010}

\begin{abstract}
In front of impacts arising from the process of urbanization, one of the ways to facilitate the improvement of life quality of urban population is to perform the planning and the planting of trees, in private or public areas. The environmental or socio-economic benefits desired with street trees come from the top of the trees and from the covering mantle formed over the streets. In this way, the goal of this research was to analyze the distribution and dynamics of crown area classes of trees measured in two inventories held in Curitiba streets trees in 1984 and 2010. Data distribution in crown area classes, for the total data and each parcel sampled, demonstrated that there is a tendency for a descending distribution curve type, typical of multi-year and multispecific stands, both for the year 1984 as for the year 2010, with greater frequency of individuals in the crown area class $0+50 \mathrm{~m}^{2}$. However, when data was analyzed for the main species it was found that for some of them the distribution curve changed from a descending type, in 1984, to a unimodal type, in 2010. There was greater_recruitment of remaining trees in classes $50-100 \mathrm{~m}^{2}$ and $100-150 \mathrm{~m}^{2}$ and larger class removal of class $0 \vdash 5 \mathrm{Om}^{2}$. It was concluded that it was possible to understand, in part, behavioral characteristics of the species and verify signs of maturing of Curitiba streets trees when analyzed 26 years later.
\end{abstract}

Keywords: Canopy cover, Shading, Tree remeasurement and Urban forest evolution.

\footnotetext{
${ }^{1}$ Recebido em 11.11.2011 e aceito para publicação em 28.05.2012.

2 Departamento de Engenharia Florestal, Unicentro, Irati, Paraná. E-mail: <bobrowski_roger@ yahoo.com.br>.

${ }^{3}$ Departamento de Ciências Florestais da Universidade Federal do Paraná, Curitiba, Paraná. E-mail: <dbiondi@ufpr.br>.
} 


\section{INTRODUÇÃO}

A alteração da paisagem natural para favorecimento da instalação de aglomerados urbanos tem ocorrido de forma mais intensa desde a Revolução Industrial, com resultados negativos sobre a qualidade de vida da população devido aos diversos tipos de impactos gerados (GONÇALVES et al., 2004).

A melhoria da qualidade de vida da população, diante dos efeitos negativos advindos do processo de urbanização, é parte do processo gerencial do poder público, o qual dispõe de diversas medidas técnicas para compatibilizar o desenvolvimento com a conservação ambiental. Segundo Bobrowski (2011), entre essas medidas estão o planejamento e implantação da arborização urbana, tanto relativa às áreas verdes quanto à arborização de ruas.

Os benefícios proporcionados pela arborização urbana são muitos (GREY; DENEKE, 1986; SILVAFILHO et al., 2002; BIONDI; ALTHAUS, 2005; WALTON, 2008; NOWAK, 2008) e podem ser derivados de diversas partes das árvores: do tronco, da folhagem, da arquitetura de copa, da floração e da frutificação. Tais benefícios podem ser de ordem ambiental, socioeconômica e estética (BOBROWSKI, 2011).

A copa é a parte da árvore que mais se destaca na arborização de ruas, pois é por meio dela que derivam os principais benefícios almejados com a implantação, crescimento e manejo da arborização, seja a redução da amplitude térmica (VELASCO, 2007), seja a absorção e filtragem da água da chuva (SILVA et al., 2010), seja a beleza estética da floração (LACERDA et al., 2011).

A expressão fenotípica da copa das árvores na arborização de ruas é influenciada por fatores ambientais que condicionam o desenvolvimento das diferentes espécies nas áreas urbanas, mas também pode ser afetada pela prática de poda que é realizada pelo poder público (ROCHA et al., 2004).

A obtenção de informações sobre a copa das árvores é relevante em inventários da arborização de ruas, pois demonstra a área de abrangência delas e os conflitos com estruturas urbanas (ALMEIDA; RONDON NETO, 2010). Informações sobre a área de copa e densidade de cobertura arbórea nos centros urbanos são importantes para a análise de índices estruturais (MACO; MCPHERSON, 2003), como os índices de áreas verdes que qualificam as cidades em qualidade ambiental (LIMA

Revista Árvore, Viçosa-MG, v.36, n.4, p.625-635, 2012
NETO; SOUZA, 2009). Para Meunier e Silva (2009), extensas áreas de copa são um dos atributos paisagísticos mais importantes da arborização urbana.

Além de índices de área verde, a análise da distribuição dos dados em classes de área de copa também é importante em estudos da arborização de ruas, pois é por meio disso que se compreende melhor a abrangência de cobertura das copas por espécie, por bairro, por unidade amostral e outros, podendo-se aferir informações sobre a sustentabilidade da arborização analisada junto com outros fatores estruturais (BOBROWSKI, 2011).

A remedição de parcelas de inventários da arborização de ruas para análise da dinâmica desse componente arbóreo não é comum no Brasil, porém é essencial para a análise do crescimento das árvores e entendimento dos padrões comportamentais das espécies utilizadas (PAIVA et al., 2007; MACHADO et al., 2010; BOBROWSKI, 2011), bem como para análise das ações de manejo adotadas pelo poder público sobre as árvores. Nos inventários da arborização de ruas, obtêm-se informações sobre as árvores em uma única etapa (ALMEIDA; RONDON NETO, 2010; PIRES et al., 2010; RABER; REBELATO, 2010; TOSCAN et al., 2010). Dessa forma, a análise de padrões comportamentais das espécies por meio da distribuição dos dados em classes fica comprometida, pois não se consegue expressar o crescimento em um período estabelecido de análise e a dinâmica da distribuição dos dados.

Em razão desse fato, os objetivos gerais desta pesquisa foram avaliar e analisar a dinâmica da área de copa das árvores na arborização de ruas da cidade de Curitiba, Paraná. Para isso, foram definidas as seguintes hipóteses: a) a distribuição dos dados em classes de área de copa se alterou no período de avaliação considerado; b) a distribuição em classes de área de copa assumiu distribuição unimodal ou decrescente; e c) a distribuição em classes de área de copa permitiu avaliar o amadurecimento da arborização e características comportamentais das espécies.

\section{MATERIAL E MÉTODOS}

\subsection{Caracterização da área de estudo}

Esta pesquisa foi realizada na cidade de Curitiba, que está localizada no primeiro planalto paranaense, entre as coordenadas $25^{\circ} 25^{\prime} 48^{\prime \prime} \mathrm{S}$ e $49^{\circ} 16^{\prime} 15^{\prime \prime} \mathrm{O}$ 
(CURITIBA, 2011). A região fitogeográfica onde se insere a cidade corresponde à Floresta Ombrófila Mista, que compõe o Bioma Mata Atlântica. O clima da região é do tipo Cfb na classificação de Köeppen, com temperaturas médias anuais nos meses quentes e frios inferiores a $22{ }^{\circ} \mathrm{C}$ e $18{ }^{\circ} \mathrm{C}$, respectivamente, e temperatura média anual igual a $17{ }^{\circ} \mathrm{C}$. A média anual da umidade relativa do ar fica em torno de $85 \%$ e a da precipitação entre 1.300 e $1.500 \mathrm{~mm}$ anuais, sem deficiência hídrica ao longo do ano (MAACK, 1981; CURITIBA, 2011).

A preocupação com a implantação da arborização de ruas em Curitiba foi iniciada a partir do século XIX, com as primeiras sugestões de plantio, e somente em 1967 houve preocupação com a ordenação do plantio, introduzindo-se espécies nativas em conjunto com aquelas já tradicionalmente utilizadas (BIONDI; ALTHAUS, 2005). Segundo dados da SMMA (2008), a contribuição em cobertura arbórea correspondente à arborização de ruas era igual a $2,48 \mathrm{~m}^{2}$ por habitante no ano de 2005.

\subsection{Procedimentos metodológicos}

A coleta de dados aconteceu entre 2009 e 2010 e foi realizada em 15 unidades amostrais de um inventário da arborização de ruas efetuado por Milano (1984). Para a localização das parcelas foram utilizados os croquis originais elaborados por ocasião da primeira medição. Esses croquis continham pontos de amarração que correspondiam a distâncias entre os limites periféricos da parcela e as esquinas das ruas avaliadas, mais próximas a cada eixo.

Em cada unidade amostral foram coletados dados relativos a variáveis dendrométricas (CAP, altura, diâmetro de copa, etc.), identificação das espécies, número predial de localização, distância entre árvores e demais medidas relacionadas à localização de cada árvore na calçada. Não foram consideradas as perdas de copa em razão da interferência para passagem ou proteção da fiação de transmissão de energia elétrica, visto que esse fato não foi observado por Milano (1984).

A identificação das espécies foi feita a campo, no momento da coleta de dados, porém para aquelas não identificadas foram coletados materiais vegetais que foram herborizados e utilizados para posterior identificação das espécies no Museu Botânico da Prefeitura de Curitiba.
Tanto para o inventário de 1984 quanto para o inventário de 2010, os dados de diâmetro de copa foram transformados em área de copa, sendo agrupados em classes com amplitude de $50 \mathrm{~m}^{2}$, tendo em vista a variabilidade de áreas de copa correspondentes à grande diversidade de espécies analisadas, bem como à diversidade de idade das árvores. Ressalta-se que não foram consideradas as alterações morfológicas promovidas pelos diferentes tipos de poda. A obtenção do diâmetro de copa na coleta de dados a campo constitui procedimento necessário à avaliação da cobertura arbórea nos inventários da arborização de ruas, tendo como exemplo os inventários realizados por Rocha et al. (2004) e Almeida e Rondon Neto (2010).

Para comparar as distribuições de cada ano de avaliação (1984 e 2010), foi aplicado o teste de Kolmogorov-Smirnov (STEPKA et al., 2010; BARRA et al., 2011) a $1 \%$ de probabilidade.

\section{RESULTADOS}

Ao todo foram amostradas 4.360 árvores em 2010, pertencentes a 122 espécies diferentes, com indívíduos arbóreos de tamanhos diversificados. Os dados de 1984 apontaram a existência de 4.348 árvores nas mesmas 15 unidades amostrais, pertencentes a 94 espécies diferentes e, também, com tamanhos variados.

A distribuição dos dados em classes de área de copa está representada na Figura 1. Em ambos os anos de avaliação houve maior concentração dos dados na primeira classe de área de copa, que corresponde ao intervalo de 0 a $50 \mathrm{~m}^{2}$. A frequência absoluta de árvores tendeu à diminuição à medida que houve aumento dos valores da classe de área de copa considerada, formando uma curva de distribuição do tipo decrescente, para os dois anos de avaliação.

Os maiores aumentos de frequência absoluta de árvores ocorreram nas classes de 100 - $150 \mathrm{~m}^{2}, 150$ - $200 \mathrm{~m}^{2}$ e $200-250 \mathrm{~m}^{2}$ (Figura 1). Nessas classes, os valores proporcionais de aumento foram respectivamente iguais a $611,76 \%, 655,56 \%$ e $985,71 \%$. Nas demais classes, mesmo naquelas com maior quantidade de árvores, o aumento proporcional foi menor.

Na classe 0 - $50 \mathrm{~m}^{2}$, o diâmetro médio da copa das árvores é igual a 3,99 m, ou seja, um raio médio de projeção para a rua igual a $1,99 \mathrm{~m}$. Já o diâmetro máximo de copa é igual a 7,98 m, ou seja, um raio máximo de projeção

Revista Árvore, Viçosa-MG, v.36, n.4, p.625-635, 2012 


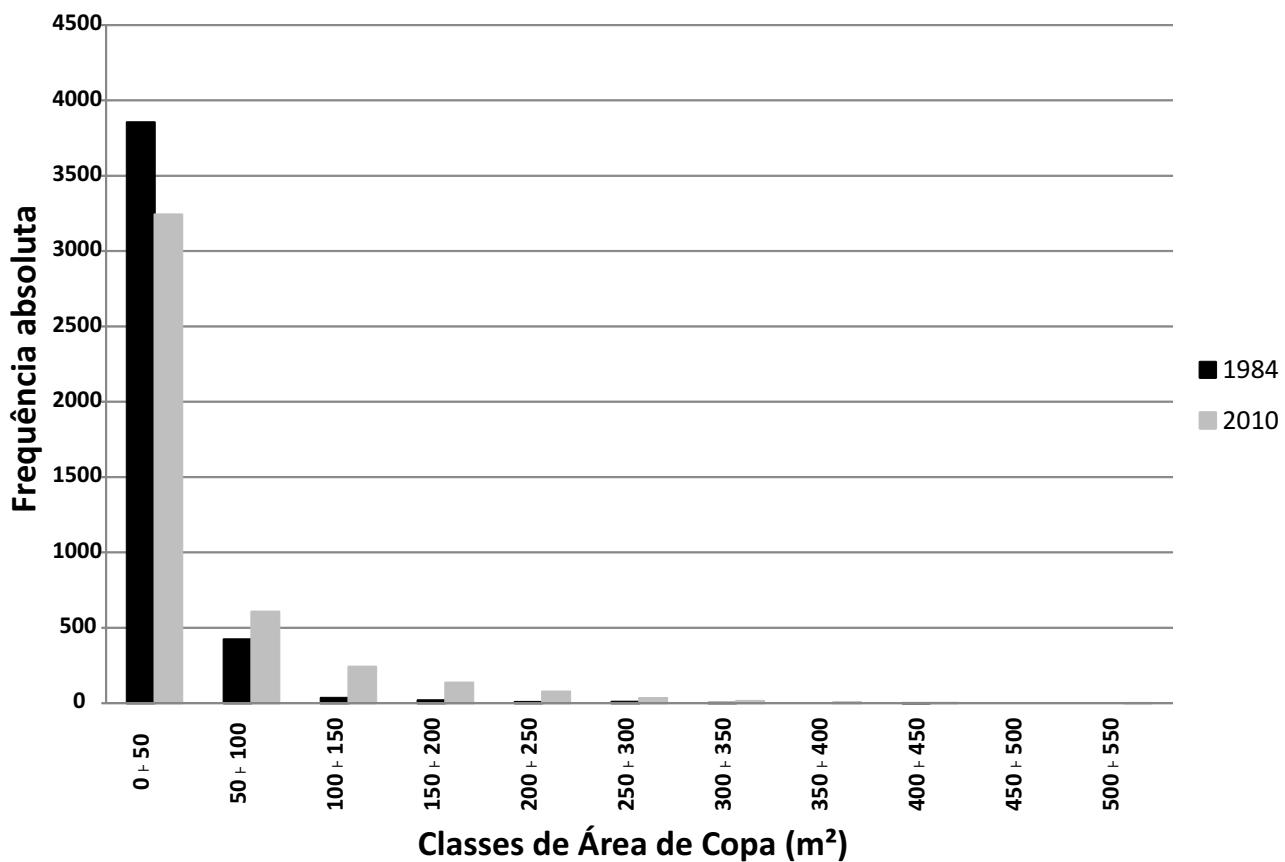

Figura 1 - Evolução da frequência absoluta de árvores por classe de área de copa, para o total amostrado, com valores de assimetria e curtose para cada ano.

Figure 1 - Tree absolute frequency evolution by crown area class for total data sampled with values for skewness and kurtosis for each year.

para a rua igual a 3,99 m. Na classe 50 - 100 m², o diâmetro médio de copa é igual a 7,98 m, ou seja, um raio médio de projeção para a rua igual a 3,99 m. Já o diâmetro máximo é igual a 15,96 m, ou seja, um raio máximo de projeção para a rua igual a 7,98 $\mathrm{m}$.

Nas classes onde houve maior aumento proporcional de árvores, os raios médios de projeção de copa para a rua são iguais a $6,31 \mathrm{~m}, 7,46 \mathrm{~m} \mathrm{e} 8,47 \mathrm{~m}$, com os respectivos diâmetros de copa iguais a 12,62 m, 14,93 m e 16,93 m.

O valor médio de área de copa das árvores teve aumento de $121,90 \%$ entre 1984 e 2010 , ou seja, aumento proporcional anual igual a $4,69 \%$ por árvore, pois os valores médios de área de copa observados em 1984 e 2010 foram, respectivamente, iguais a $18,95 \mathrm{~m}^{2} \mathrm{e}$ 42,05 m², em relação ao total amostrado. Já os valores máximos de área de copa, por árvore, chegaram a 415,48 m² em 1984 e 500,74 m² em 2010.

O resultado da análise estatística das distribuições em classes de área de copa, tanto para cada parcela quanto para o total, encontra-se na Tabela 1 . O teste de Kolmogorov-Smirnov aplicado às distribuições demonstrou não haver diferença estatisticamente
Tabela 1 - Resultados do teste de Kolmogorov-Smirnov na análise comparativa da distribuição dos dados em classes de área de copa, por parcela e para o total. (**) significativo a $1 \%$ de probabilidade; e (ns) não significativo.

Table 1 -Kolmogorov-Smirnov test results in the comparative analysis of crown area classes data distribution, by unit plot and total data sampled. (**) statistically significant at the level of $1 \%$ of probability, $(n s)$ not statistically significant.

\begin{tabular}{lcc}
\hline Parcelas & Dmáxcalc & Dmáxtab \\
\hline Água Verde & $0,15730^{* *}$ & 0,05778 \\
Alto da XV & $0,05530^{\text {ns }}$ & 0,07365 \\
Bacacheri 01 & $0,41611^{* *}$ & 0,09490 \\
Bacacheri 02 & $0,23177^{* *}$ & 0,08370 \\
Bacacheri 03 & $0,09835^{\text {ns }}$ & 0,12967 \\
Bigorrilho & $0,19462^{* *}$ & 0,06967 \\
Boqueirão & $0,08527^{\text {ns }}$ & 0,25702 \\
Centro & $0,27028^{* *}$ & 0,12313 \\
Cristo Rei & $0,28169^{* *}$ & 0,08014 \\
Jardim Social & $0,16806^{* *}$ & 0,05891 \\
Mercês & $-0,14018^{* *}$ & 0,07311 \\
Portão & $0,32366^{* *}$ & 0,08171 \\
Rebouças 01 & $0,27198^{* *}$ & 0,12909 \\
Rebouças 02 & $0,09127^{* *}$ & 0,06817 \\
Seminário & $0,13400^{* *}$ & 0,07852 \\
\hline Total & $0,14281^{* *}$ & 0,02063 \\
\hline
\end{tabular}


significativa nas parcelas Alto da XV, Bacacheri 03 e Boqueirão $(p>0,01)$, porém nas demais parcelas constatou-se que a diferença foi significativa $(p<0,01)$, o que denota não haver aderência entre as distribuições.

Quando analisados os dados por parcela (Figura 2.A. e Figura 2.B.), constatou-se que foi mantida a tendência de distribuição em uma curva decrescente de 1984 para 2010, assim como para o total amostrado em cada ano. Porém, quando analisados os dados para as principais espécies (Figura3), a tendência não se manteve, pois para algumas delas houve mudança para uma curva tipicamente unimodal em 2010.

A Figura 3 apresenta a distribuição em classes de área de copa das oito principais espécies remanescentes. Entre os anos de 1984 e 2010, as curvas de distribuição mantiveram a tendência decrescente para as espécies Acer negundo (acer), Ligustrum lucidum (alfeneiro) e Handroanthus albus (ipê-amarelograúdo); mudaram de forma indefinida, representada por uma única classe, para decrescente nas espécies Lagerstroemia indica (extremosa) e Handroanthus chrysotrichus (ipê-amarelo-miúdo); e mudaram de decrescente para uma curva unimodal nas espécies Cassia leptophylla (falso-barbatimão), Parapiptadenia rigida (angico) e Tipuana tipu (tipuana).

A dinâmica da área de copa analisada para cada classe e para o total da arborização de ruas está representada na Tabela 2, sendo analisada em relação às árvores remanescentes no período 1984-2010. Observa-se que $63,97 \%$ das árvores permaneceram dentro das mesmas classes de área de copa, com maior proporção para a classe de $0-50 \mathrm{~m}^{2}$. A maior frequência absoluta de remoção de árvores com recrutamento nas classes superiores foi observada na classe $0-50 \mathrm{~m}^{2}$, pois essa classe apresentava maior frequência de árvores em 1984. Já a maior frequência de ingresso de árvores foi observada para a classe de $50-100 \mathrm{~m}^{2}$, porém sendo também expressivo o recrutamento de árvores na classe de 100 - $150 \mathrm{~m}^{2}$.

O saldo líquido foi positivo e com maior frequência absoluta para a classe $100+150 \mathrm{~m}^{2}$, seguido em menor frequência nas demais classes, exceto $0-50 \mathrm{~m}^{2}$, em que o saldo líquido foi negativo.

\section{DISCUSSÃO}

A distribuição dos dados nas classes de área de copa seguiu a tendência decrescente, em forma de "J invertido", tanto em 1984 quanto em 2010 (Figura 1), evidenciando o caráter multiâneo e multiespecífico da arborização analisada. Almeida e Rondon Neto (2010) também constataram essa tendência na distribuição dos dados em classes de diâmetro de copa na arborização de ruas das cidades de Colíder e Matupá, Mato Grosso.

A menor assimetria entre as classes em 2010 (Figura 1) se deve à observação de copas com áreas maiores, diluindo o quantitativo por todas as classes, pois houve redução de frequência na primeira classe e aumento nas demais. A redução dos valores de assimetria e curtose entre os anos de 1984 e 2010 sugere que a distribuição dos dados em classes de área de copa se tornou mais simétrica em 2010, com curva menos abrupta, em relação a 1984. Segundo Machado et al. (2006), medidas de dispersão como assimetria e curtose servem para descrever a forma e evolução das curvas de distribuição, em relação à curva de distribuição normal.

As maiores diferenças entre as frequências das classes 0 - $50 \mathrm{~m}^{2}$ e $50-100 \mathrm{~m}^{2}$, observadas nas parcelas Água Verde, Bacacheri 03, Jardim Social e Rebouças 02, tanto em 1984 quanto em 2010 (Figura 2.A. e Figura 2.B.), sugerem que haja maior número de árvores pequenas, concentradas na primeira classe, provenientes de plantios mais recentes ou plantios de espécies que possuem tendência a desenvolver copas de pequenas dimensões, como L. indica e H. chrysotrichus.

Nas parcelas Bacacheri 01 e Portão, constatou-se que a distribuição das áreas de copa, apesar da característica decrescente, se apresentou menos abrupta e mais simétrica entre as classes. Esse fato pode ser explicado pelo equilíbrio quantitativo entre árvores com grande área de copa e espécies com pequena dimensão de copa ou provenientes de plantios mais recentes efetuados com o objetivo de revitalizar a arborização do local. Entretanto, conforme demonstrado na Figura 2.A., na parcela Bacacheri 01 há expressiva frequência de árvores com área de copa na classe de $100-150 \mathrm{~m}^{2}$ e maiores, essencialmente compostas por árvores de $P$. rigida (angico), que segundo Biondi e Althaus (2005) é uma espécie de grande porte.

Na parcela Mercês, o aumento da frequência de árvores com área de copa na classe de 0 - $50 \mathrm{~m}^{2}$ entre 1984 e 2010 se deve muito mais às podas drásticas efetuadas sobre os indivíduos de Ligustrum lucidum (alfeneiro), alterando sua forma e área, do que a contribuição de novos plantios de espécies com copa de pequena extensão. Essa espécie compunha mais 

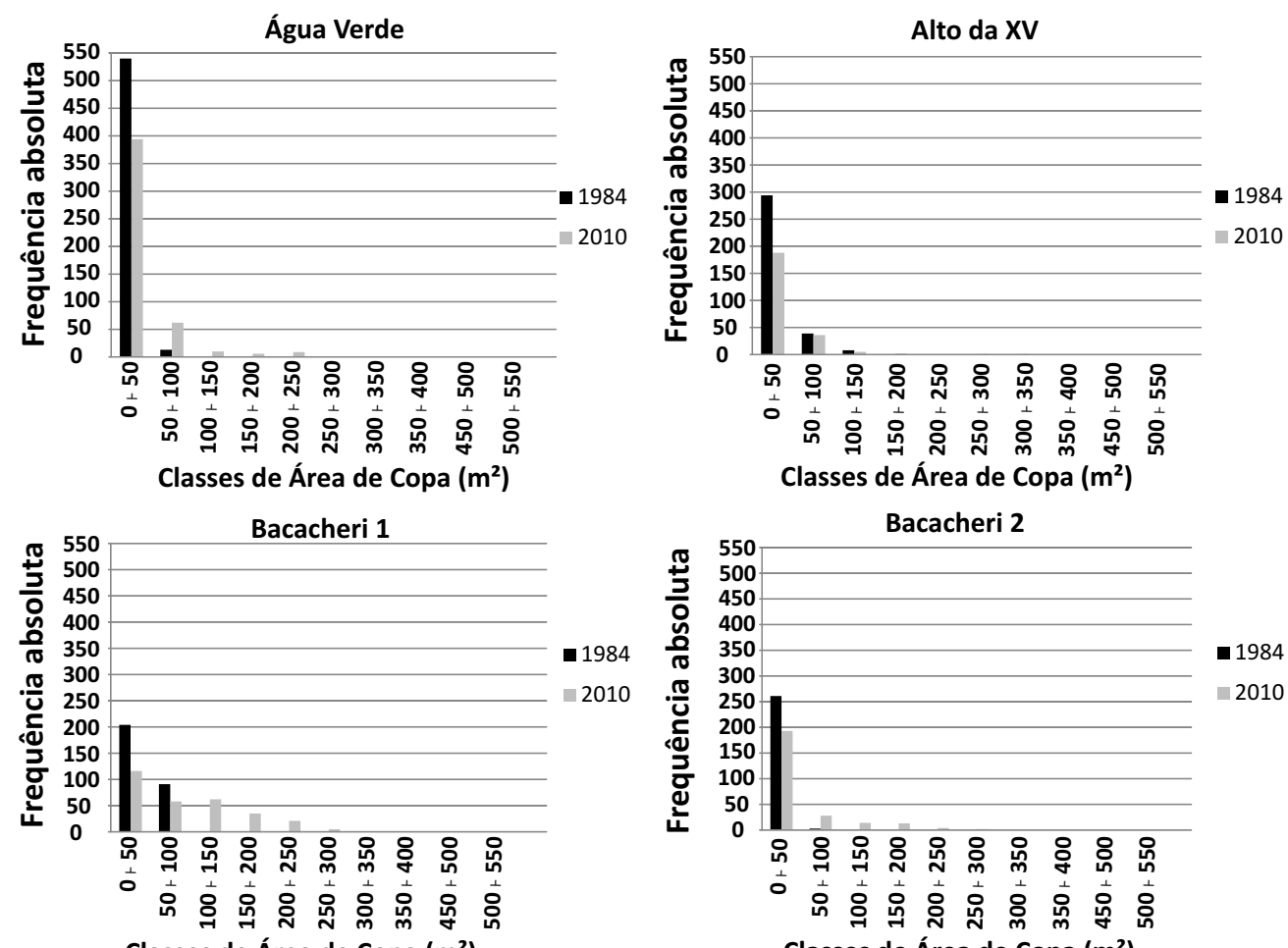

Classes de Área de Copa $\left(\mathrm{m}^{2}\right)$

Classes de Área de Copa $\left(\mathrm{m}^{2}\right)$
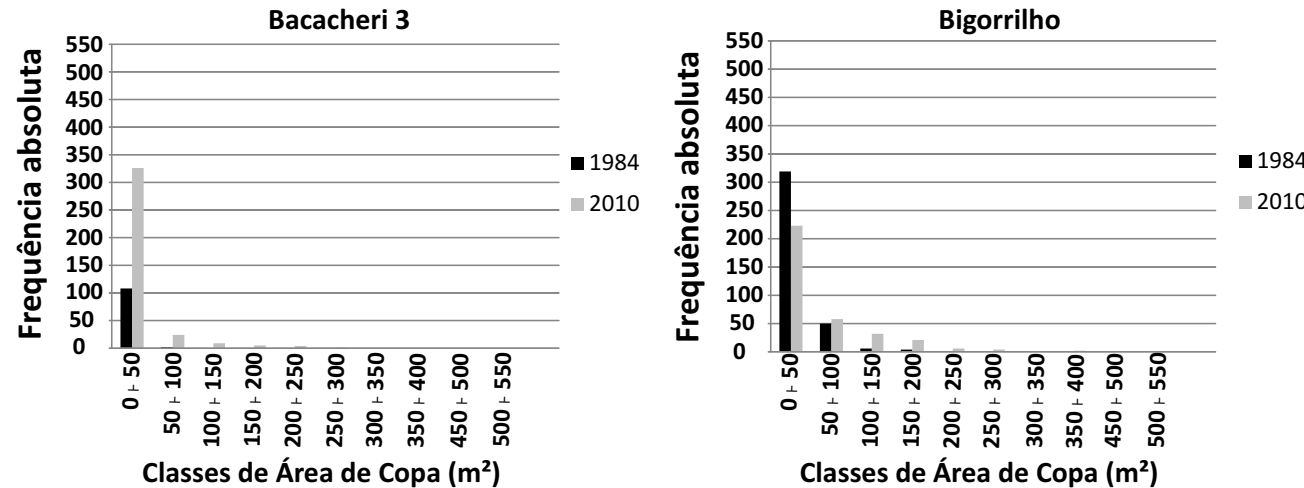

Classes de Área de Copa $\left(\mathrm{m}^{2}\right)$
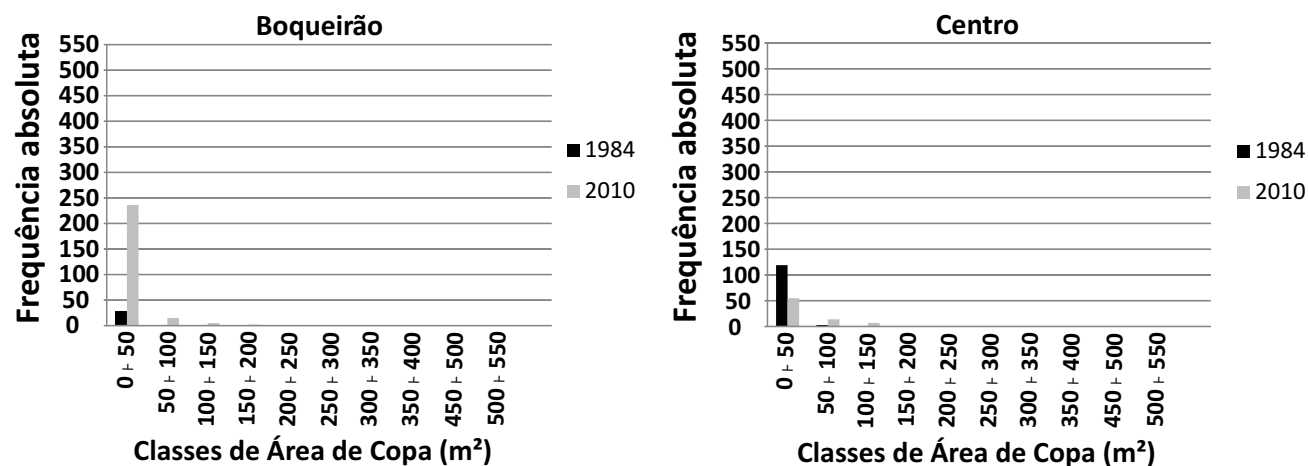

Figura 2.A. - Evolução da distribuição dos dados em classes de área de copa $\left(\mathrm{m}^{2}\right)$ em cada parcela amostrada. Figure 2.A. - Data distribution evolution in crown area classes $\left(m^{2}\right)$ for each plot sampled. 

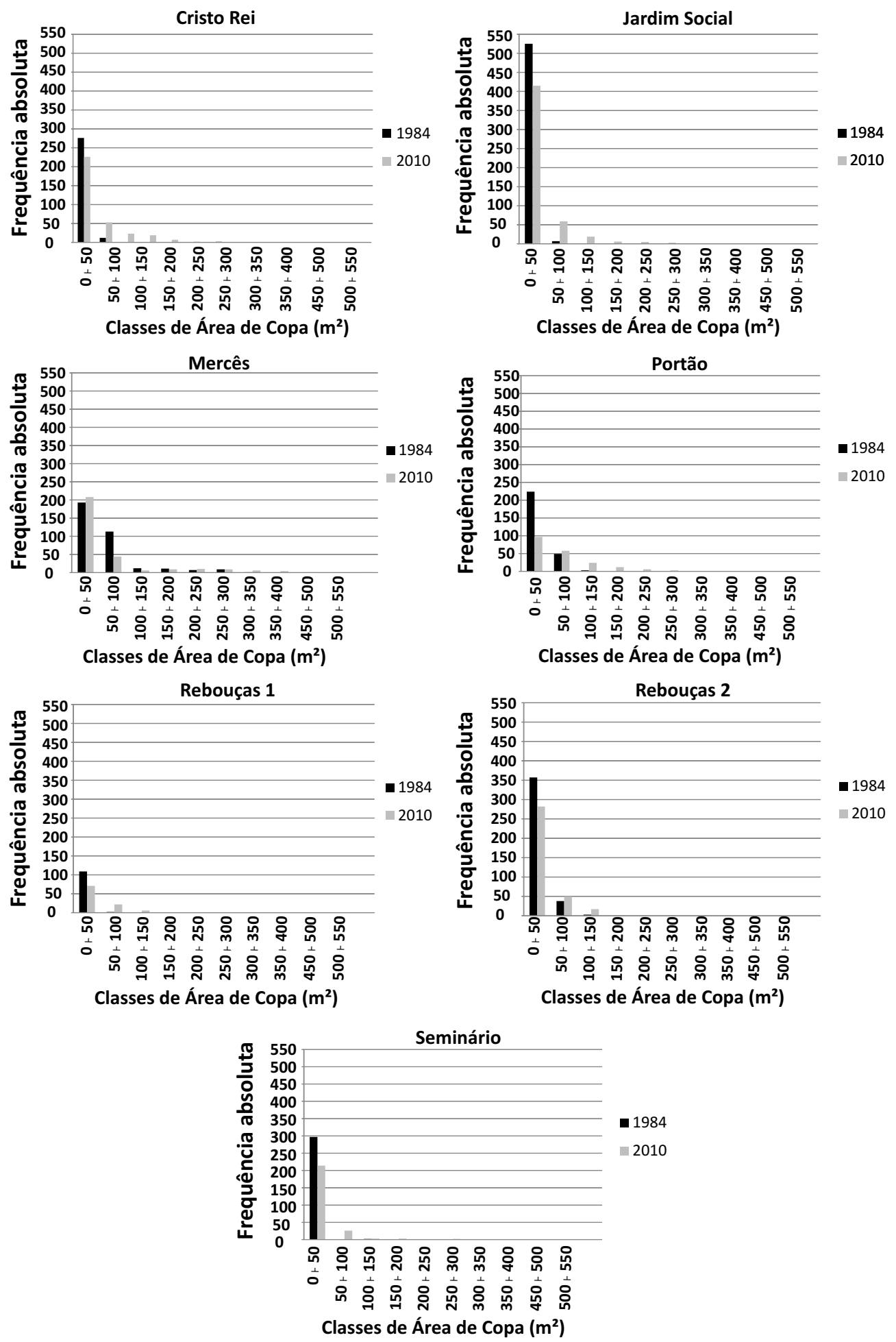

Figura 2.B. - Evolução da distribuição dos dados em classes de área de copa $\left(\mathrm{m}^{2}\right)$ em cada parcela amostrada. Figure 2.B. - Data distribution evolution in crown area classes $\left(\mathrm{m}^{2}\right)$ for each plot sampled. 

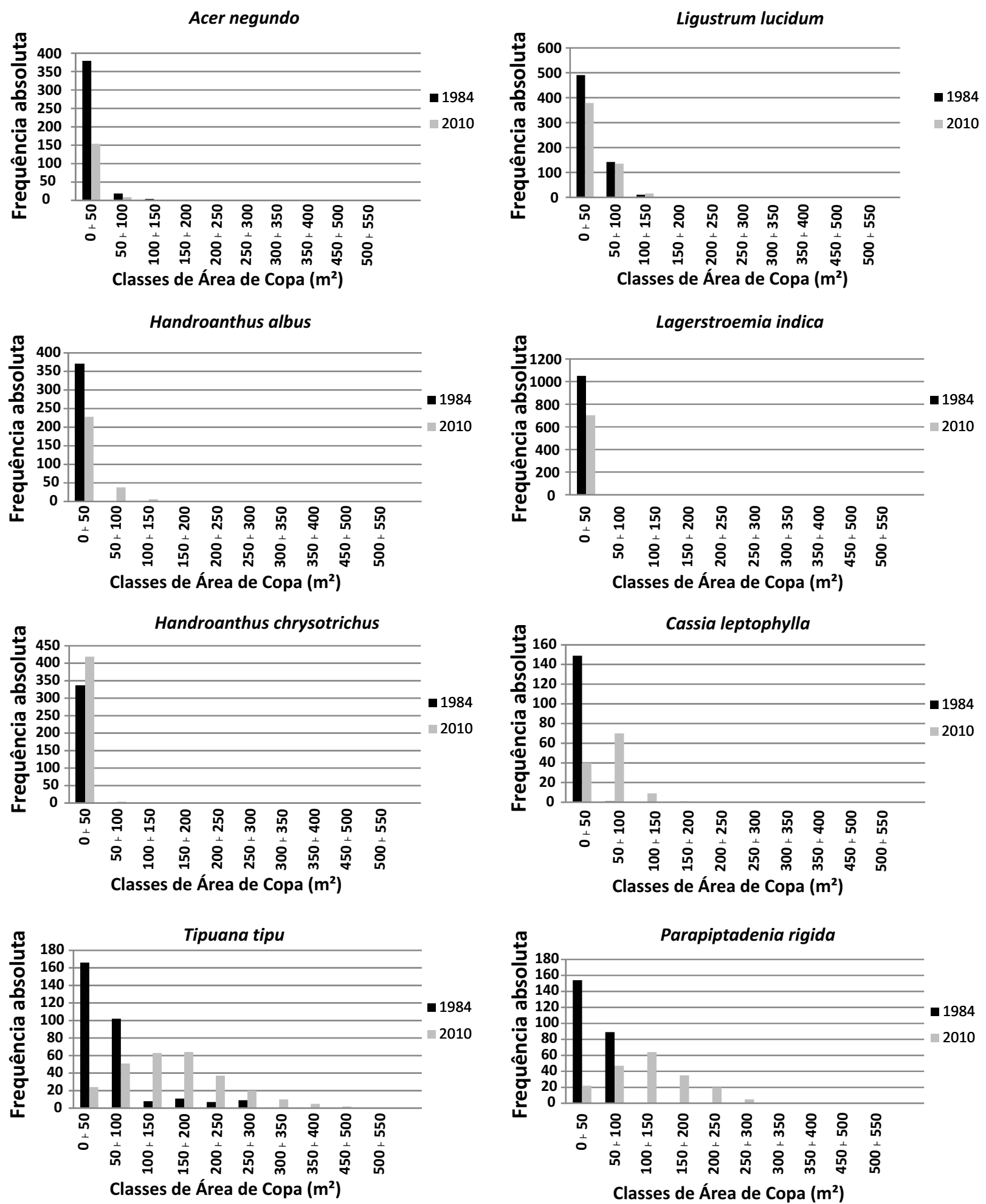

Figura 3 - Distribuição das classes de área de copa das principais espécies remanescentes entre 1984 e 2010.

Figure 3 - Crown area classes distribution for the main species remaining between 1984 and 2010.

Revista Árvore, Viçosa-MG, v.36, n.4, p.625-635, 2012 
Tabela 2 - Dinâmica da quantidade de árvores nas classes de área de copa definidas (T84 - total de árvores em cada classe em 1984 e que foram observadas como remanescentes em 2010 (não necessariamente na mesma classe); T10 - total de árvores remanescentes em cada classe em 2010, em relação aos dados de 1984; TRE - total de árvores remanescentes na classe; TRM - total de árvores removidas da classe; TIN - total de árvores ingressantes na classe; SLIQ - saldo líquido; PI - proporção em relação ao número inicial; e PF - proporção em relação ao número final).

Table 2 - Dynamics of the amount of trees on defined crown area classes. (T84 - total of trees existing in each class in 1984 and that were observed as remaining in 2010 (not necessarily in the same class); T10 - total of trees remaining in each class in 2010, relating to the 1984 data; TRE - total remaining trees in the class; TRM - total removed trees from the class; TIN - total recruited trees in the class; SLQ - net balance; PI - proportion in relation to the initial number; PF - proportion in relation to the final number).

\begin{tabular}{crrrrrrrrr}
\hline Classes de copa & T84 & \multicolumn{1}{c}{ T10 } & \multicolumn{1}{c}{ TRE } & PI $(\%)$ & TRM & PI $(\%)$ & TIN & PF $(\%)$ & SLQ \\
\hline $0+50$ & 1638 & 1152 & 1107 & 67,58 & 531 & 32,42 & 45 & 3,91 & -486 \\
$50+100$ & 269 & 382 & 127 & 47,21 & 142 & 52,79 & 255 & 66,75 & 113 \\
$100+150$ & 20 & 183 & 11 & 55,00 & 9 & 45,00 & 172 & 93,99 & 163 \\
$150+200$ & 12 & 121 & 3 & 25,00 & 9 & 75,00 & 118 & 97,52 & 109 \\
$200+250$ & 6 & 66 & 2 & 33,33 & 4 & 66,67 & 64 & 96,97 & 60 \\
$250+300$ & 8 & 28 & 0 & 0,00 & 8 & 100,00 & 28 & 100,00 & 20 \\
$30+350$ & 1 & 13 & 0 & 0,00 & 1 & 100,00 & 13 & 100,00 & 12 \\
$350+400$ & 0 & 6 & 0 & 0,00 & 0 & 0,00 & 6 & 100,00 & 6 \\
$400+450$ & 0 & 2 & 0 & 0,00 & 0 & 0,00 & 2 & 100,00 & 2 \\
$450+500$ & 0 & 0 & 0 & 0,00 & 0 & 0,00 & 0 & 0,00 & 0 \\
$500+550$ & 0 & 1 & 0 & 0,00 & 0 & 0,00 & 1 & 100,00 & 1 \\
\hline Total & 1954 & 1954 & 1250 & 63,97 & 704 & 36,03 & 704 & 36,03 & 0 \\
\hline
\end{tabular}

de $50 \%$ do total arbóreo da amostra e está entre aquelas declaradas exóticas invasoras (BIONDI; PEDROSAMACEDO, 2008). A produção e respectivo plantio da espécie estão em desuso pela prefeitura municipal (BOBROWSKI, 2011).

A mudança de curva decrescente para unimodal apresentou-se como leve tendência para C. leptophylla (Figura 3), entretanto para $P$. rigida e T. tipu a distribuição das classes de área de copa em curva unimodal apresentou-se de forma mais proeminente. Nessas duas últimas espécies, a maior frequência de área de copa das árvores mudou para ambas as classes $0-50 \mathrm{~m}^{2}$ nas respectivas classes de $100-150 \mathrm{~m}^{2} \mathrm{e}$ $150-200 \mathrm{~m}^{2}$. Isso evidencia a característica das espécies em expressar grande área de copa (BIONDI; ALTHAUS, 2005) e pode sugerir que há moderada taxa de plantio ou reposição das espécies, porém com maior concentração de árvores em estágio de maturidade provendo benefícios máximos.

Nas espécies L. indica e H. chrysotrichus, quase a totalidade da frequência de árvores se deu na classe de $0-50 \mathrm{~m}^{2}$. Isso evidencia a característica de pequena projeção de copa dessas espécies, úteis para locais onde haja limitação de espaço em função de calçadas com pequena dimensão ou inexistência de recuo frontal das residências. Porém, a espécie $H$. chrysotrichus não é indicada para plantio sob a fiação devido à forma ortotrópica de sua arquitetura de copa, o que limita a condução da árvore para além da fiação.

Apesar da manutenção da tendência de curva decrescente, A. negundo apresentou distribuição menos proeminente em 2010 em razão, possivelmente, das remoções de árvores adultas dessa espécie, por problemas fitossanitários e estruturais consequentes (BOBROWSKI, 2011), o que pode ter interferido na expressão real da distribuição de área de copa da espécie.

Com relação à dinâmica da área de copa analisada para cada classe e para o total da arborização de ruas, observou-se que a permanência de maior proporção de árvores remanescentes na classe 0 - 50 m² (Tabela 2), entre 1984 e 2010, se deve a espécies como L. indica e H. chrysotrichus, que possuem característica de copa com pequena dimensão, com diâmetro entre 4,0-6,0 m (BIONDI, ALTHAUS, 2005), ou a espécie como $L$. lucidium, na qual foi observada maior intensidade de podas de rebaixamento e drástica, que podem impedir a projeção da copa em maior extensão de área.

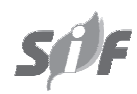

Revista Árvore, Viçosa-MG, v.36, n.4, p.625-635, 2012 
A maior frequência absoluta de remoção de árvores da classe 0 - $50 \mathrm{~m}^{2}$ de 1984 com recrutamento nas classes superiores em 2010 se deve ao crescimento em área de copa das árvores, pois essa classe apresentava maior frequência de árvores em 1984. A maior frequência de ingresso de árvores foi observada na classe de 50 $100 \mathrm{~m}^{2}$, em 2010 , porém sendo também expressivo o recrutamento de árvores na classe de $100-150 \mathrm{~m}^{2}$. As árvores integrantes dessas duas classes possuem raio médio de copa entre 5,0 - 6,0 m, o que possibilita bom recobrimento da rua, quase atingindo a faixa central de ruas mais estreitas.

O saldo líquido foi positivo e com maior frequência absoluta na classe de $100-150 \mathrm{~m}^{2}$ (Figura 1), seguido em menor frequência nas demais classes, exceto a de 0 - $50 \mathrm{~m}^{2}$, em que o saldo líquido foi negativo. $\mathrm{O}$ aumento dos valores de saldo líquido nas classes superiores a $100-150 \mathrm{~m}^{2}$ demonstra a tendência das árvores remanescentes, por meio da expansão das áreas de copa, em contribuir e potencializar os benefícios proporcionados pela arborização de ruas, por formarem um manto de cobertura e sombreamento. Entretanto, maiores áreas de copa podem gerar maiores riscos potenciais de danos e acidentes por queda de galhos de grande porte ou de árvores inteiras, se não adotadas medidas adequadas de manejo (em frequência, intensidade e técnica). Então, é salutar contrabalançar os benefícios requeridos e possíveis com os custos e problemas advindos com as opções de plantio feitas, principalmente, por meio de maior frequência no monitoramento das árvores por parte do órgão responsável pela arborização da cidade.

\section{CONCLUSÕES}

A distribuição dos dados em classes de área de copa permitiu compreender, em parte, características comportamentais das espécies utilizadas na arborização de ruas, bem como o comportamento da arborização analisada como um todo e do espaço ocupado pelas árvores nas calçadas.

No total de dados amostrados não houve alteração da curva de distribuição em classes de área de copa no período 1984-2010, permanecendo a curva com forma decrescente. Porém, quando analisados os dados das principais espécies, observou-se que a curva mudou de decrescente para unimodal nas espécies $C$. leptophylla, P. rigida e T. tipu.

Revista Árvore, Viçosa-MG, v.36, n.4, p.625-635, 2012
A dinâmica da distribuição dos dados com ingresso em classes de maior área de copa sugere que a arborização analisada possui sinais de amadurecimento, por ser composta por indivíduos adultos com grande área de copa, além daqueles remanescentes do inventário de 1984, que migraram para classes de maior área de copa.

\section{REFERÊNCIAS}

ALMEIDA, D. N.; RONDON NETO, R. M. Análise da arborização urbana de duas cidades da região norte do Estado de Mato Grosso. Revista Árvore, v.34, n.5, p.899-906, 2010.

BARRA, O. S. V. et al. Proposta metodológica para o ajuste ótimo da distribuição diamétrica SB de Johnson. . Revista Árvore, v.35, n.1, p.151-156, 2011.

BIONDI, D.; ALTHAUS, M. Árvores de rua de Curitiba: cultivo e manejo. Curitiba: FUPEF, 2005.

BIONDI, D.; PEDROSA-MACEDO, J. H. Plantas invasoras encontradas na área urbana de Curitiba (PR). Revista Floresta, v.38, n.1, p.129-144, 2008.

BOBROWSKI, R. Estrutura e dinâmica da arborização de ruas de Curitiba, Paraná, no período 1984 - 2010. 2011.144f. Dissertação (Mestrado em Engenharia Florestal) -Universidade Federal do Paraná, Curitiba, 2011.

CURITIBA - PREFEITURA MUNICIPAL. Perfil de Curitiba. Curitiba, 2011. Disponível em: http://www.curitiba.pr.gov.br/conteudo/perfil-dacidade-de-curitiba/174. Acesso em: 12/01/2011.

GONÇALVES, E. O. et al. Avaliação qualitativa de mudas destinadas à arborização urbana no Estado de Minas Gerais. . Revista Árvore, v.28, n.4, p.479-489, 2004.

GREY, G. W.; DENEKE, F. J. Urban forestry. 2.ed. New York: J. Wiley, 1986. 199p.

LACERDA, R. M. A.; LIRA FILHO, J. A.; SANTOS, R. V. Indicação de espécies de porte arbóreo para a arborização urbana no semi-árido Paraibano. Revista da Sociedade Brasileira de Arborização Urbana, v.6, n.1, p.51-68, 2011. 
LIMA NETO, E. M.; SOUZA, R. M. Índices de densidade e sombreamento arbóreo em áreas verdes públicas de Aracajú, Sergipe. Revista da Sociedade Brasileira de

Arborização Urbana, v.4, n.4, p.47-62, 2009.

MAACK, R. Geografia Física do Estado do Paraná. 2.ed. Curitiba: BADEP/UFPR/IBPT, 1981.

MACO, S. E.; MCPHERSON, E. G. A practical approach to assessing structure, function, and value of street tree populations in small communities. Journal of Arboriculture, v.29, n.2, p.84-97, 2003.

MACHADO, S. A. et al. Dinâmica da distribuição diamétrica de bracatingais na região metropolitana de Curitiba. Revista Árvore, v.30, n.5, p.759-768, 2006.

MACHADO, E. L. M. et al.Flutuações temporais nos padrões de distribuição diamétrica da comunidade arbóreo-arbustiva e de 15 populações em um fragmento florestal. . Revista Árvore, v.34, n.4, p.723-732, 2010.

MEUNIER, I. M. J.; SILVA, H. C. G. Horto D'el Rey de Olinda, Pernambuco: história, estado atual e potencialidades da cobertura vegetal de uma área verde urbana (quase) esquecida. Revista da Sociedade Brasileira de

Arborização Urbana, v.4, n.2, p.62-81, 2009.

MILANO, M. S. Avaliação e análise da arborização de ruas de Curitiba-PR. 1984.130f. Dissertação (Mestrado em Engenharia Florestal) - Universidade Federal do Paraná, Curitiba, 1984.

NOWAK, D. J. et al. Effect of plot and sample size on timing and precision of Urban Forest Assessments. Arboriculture and Urban Forestry, v.34, n.6, p.386-390, 2008.

PAIVA, L. V.; ARAÚJO, G. M.; PEDRONI, F. Structure and dynamics of a woody plant community of a tropical semi-deciduous seasonal forest in "Estação Ecológica do Panga", municipality of Uberlândia, Minas Gerais, Brazil. Revista Brasileira de Botânica, v.30, n.03, p.365-373. 2007.

PIRES, N. A. M. T. et al. arborização urbana do município de Goiandira/GO - caracterização qualiquantitativa e proposta de manejo. Revista da Sociedade Brasileira de Arborização Urbana, v.5, n.3, p.185-205, 2010.
RABER, A. P.; REBELATO, G. S. Arborização viária no município de Colorado, RS - Brasil: análise quali-quatitativa. Revista da Sociedade Brasileira de Arborização Urbana, v.5, n.1, p.193-199, 2010.

ROCHA, R. T.; LELES, P. S. S.; OLIVEIRA NETO, S. N. Arborização de vias públicas em Nova Iguaçú, RJ: o caso dos bairros Rancho Novo e Centro. Revista Árvore, v.28, n.4, p.599-607, 2004.

SILVA FILHO, D. F. et al. Banco de dados relacional para cadastro, avaliação e manejo da arborização em vias públicas. . Revista Árvore, v.26, n.5, p.629-642, 2002.

SILVA, L. F. et al. Interceptação da chuva por duas espécies arbóreas em áreas verdes urbanas. Cerne, v.16, n.4, p.547-555, 2010.

SECRETARIA MUNICIPAL DE MEIO AMBIENTE - SMMA. Plano Municipal de Controle Ambiental e Desenvolvimento Sustentável. Curitiba: 2008. Disponível em: http://www.curitiba.pr.gov.br/multimidia/ 00085324.pdf. Acesso em: 14 de mar. de 2011.

STEPKA, T. F. et al. Prognose da estrutura diamétrica de uma Floresta Ombrófila Mista com os métodos razão de movimentos e matriz de transição. Pesquisa Florestal Brasileira, v.30, n.64, p.327-335, 2010.

TOSCAN, M. A. G. et al. Inventário e análise da arborização do bairro Vila Yolanda, do município de Foz do Iguaçú-PR. Revista da Sociedade Brasileira de Arborização Urbana, v.5, n.3, p.165-184, 2010.

VELASCO, G. D. N. Potencial da

arborização viária na redução do consumo de energia elétrica: definição de três áreas na cidade de São Paulo SP, aplicação de questionários, levantamento de fatores ambientais e estimativa de Graus-Hora de calor. 2007. 122f. Tese (Doutorado em Agronomia) Escola Superior de Agricultura "Luiz de Queiroz", Universidade de São Paulo, Piracicaba, 2007.

WALTON, J. F.; NOWAK, D. J.; GREENFIELD, E. J. Assessing Urban Forest Canopy cover using airbone or satellite imagery. Arboriculture and Urban Forestry, v.34, n.6, p.334-340, 2008.

Revista Árvore, Viçosa-MG, v.36, n.4, p.625-635, 2012 
